\title{
Detection of abrupt changes in glacier mass balance in the Tien Shan Mountains
}

\author{
M. S. CaO \\ Lanzhou Institute of Glaciology and Geocryology, Chinese Academy of Sciences, Lanzhou 730000, China
}

\begin{abstract}
Based on glacier mass-balance records collected, compiled and published by the World Glacier Monitoring Service (WGMS), an attempt is made here to determine whether there were abrupt decadal-scale changes in annual balance on glaciers in the Tien Shan Mountains. There appears to have been an abrupt change in the mid1970s: two-thirds of the change was caused by an increase in annual ablation and the other one-third by a decrease in the annual accumulation. Thus, the change was caused mainly by a summer-temperature increase, supplemented by a decrease in annual snowfali. Climate records suggest that this event, in effect, is in response to a shift in the background state of the coupled ocean-atmosphere system over the Tropical Pacific during the mid1970 s.
\end{abstract}

\section{INTRODUCTION}

Since the 1970s, abrupt changes in climate have been attracting increased attention. Climate researchers are frequently detecting new abrupt events at different time-scales, analyzing their characteristics, and discussing dynamic mechanisms (Goossens and Berger, 1987). For example, although annual temperature departures over the Northern Hemisphere have often varied from positive to negative, or conversely, since 1851, statistical analysis has shown that there was, in fact, a significant shift in temperature from a colder to a warmer regime in the early 1920s (Yamamoto and others, 1985).

Glaciers are an important environmental feature in high mountain areas. In a given mountain area, climate change directly influences the size, flow rate and even the existence of glaciers. Conversely, glacial fluctuations lead indirectly to the preservation of records of significant changes in climate. For example, based on the analysis of $\delta^{18} \mathrm{O}$ records in oceansediment cores, statistical studies show that there was an abrupt change in climate about $900 \mathrm{ka}$ BP, in the middle of the Pleistocene, involving worldwide cooling and an increase in ice mass (Maasch, 1988). Mountain glaciers and small ice caps are particularly sensitive to climate and it has been suggested that they could be used to monitor environmental or climatic changes (Meier, 1965; Barry, 1985). Several recent studies have discovered an abrupt change in climate in the tropical and North Pacific Ocean in the mid1970s (Trenberth, 1990; Graham, 1994). Here, an attempt is made to determine whether this change affected glacier mass balance in the Tien Shan Mountains, using statistical tests.

\section{DATA}

Because most glaciers are located in sparsely populated, cold, high-mountain areas, field work is difficult and data on glacier fluctuations are scarce. Less than about $1 \%$ of the glaciers in the world are surveyed, and less than onetenth of those surveyed have been measured for mass balance. Systematic measurements, starting in the mid1950s have resulted in valuable records (Wood, 1988). The World Glacier Monitoring Service (WGMS) has collected and compiled available datasets and published six volumes of data on mass balance and glacier fluctuations (Kasser, 1967, 1973; Müller, 1977; Haeberli, 1985, Haeberli and Müller, 1988, Haeberli and Hoelzle, 1993).

The Tien Shan Mountains range in Central Asia is about $2100 \mathrm{~km}$ long and 250-400 km wide (Fig. 1). According to a recent inventory, there are 16490 glaciers in the range, of which only three, Ts. Tuyuksu, Karabatkak and Urumqi No. 1 , or $0.02 \%$ of the total, have mass-balance records more than 26 years long. All of the data used here have been published in the previously mentioned WGMS publications with modifications according to the latest corrected data (Dyurgerov and others, 1995) and are given in Table 1. The data for Urumqi glacier No. 1 have been reconstructed for 1967-78 using records from a nearby meteorological station. The locations and some characteristics of the three glaciers discussed here are shown in Figure 1 and Table 2, respectively. Although mass-balance data are available in the WGMS reports for eight other glaciers near Ts. Tuyuksu, most of the data have been reconstructed and all of the glaciers are located in the same small basin. Hence, these are not discussed here.

Precipitation in the Tien Shan Mountains is concentrated in the spring and summer and, in fact, shifts from spring to summer as one moves from west to east. For example, in the Ts. Tuyuksu basin, $7 \%$ of the precipitation occurs in the winter (December-February), $35 \%$ in the spring (March-May) and 43\% in the summer (June August), whereas in the Urumqi glacier No. 1 basin the corresponding percentages are 2,18 and $66 \%$. Thus, a significant fraction of the accumulation occurs during the ab- 


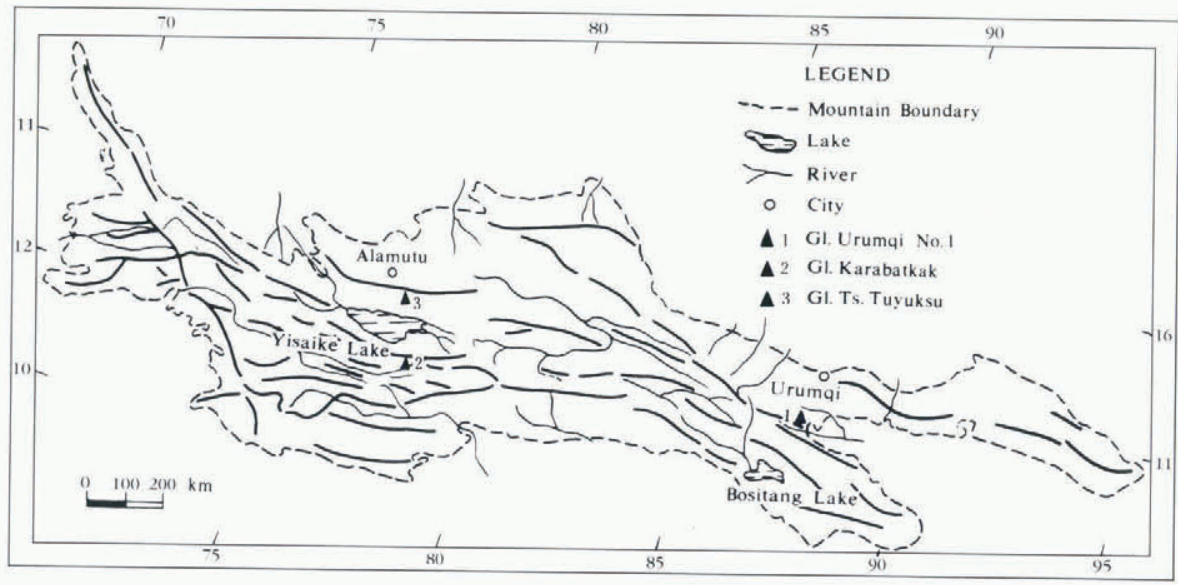

Fig. 1. Locations of the three glaciers studied.

Table 1. The observational records ( $\mathrm{mm}$ ) of annual accumulation $(C)$, ablation $(A)$ and mass balance $(B)$ on three glaciers in the Tien Shan Mountains

\begin{tabular}{rrrrrrrrrrr}
\hline Year & \multicolumn{3}{c}{ T. Tuyuksu } & \multicolumn{3}{c}{ Karabatkak } & \multicolumn{2}{c}{ Crumqiglacier. No. I } \\
& $C$ & $A$ & $B$ & $C$ & $A$ & $B$ & $C$ & $A$ & $B$ \\
& & & & & & & & & \\
\hline $56-57$ & 1070 & 1220 & -150 & & & & & & \\
$57-58$ & 1250 & 920 & 330 & & & & & & \\
$58-59$ & 970 & 1390 & -420 & 737 & 1081 & -344 & 543 & 456 & 87 \\
$59-60$ & 1090 & 1190 & -100 & 666 & 957 & -291 & 608 & 796 & -188 \\
$60-61$ & 920 & 1480 & -560 & 474 & 1280 & -806 & 630 & 663 & -33 \\
$61-62$ & 870 & 1560 & -690 & 656 & 742 & -86 & 624 & 791 & -167 \\
$62-63$ & 1290 & 850 & 440 & 666 & 706 & -40 & 633 & 399 & 234 \\
63 & 64 & 1320 & 800 & 520 & 893 & 749 & 144 & 589 & 587 & 2 \\
$64-65$ & 1160 & 1210 & -50 & 711 & 752 & -41 & 650 & 276 & 374 \\
$65-66$ & 1120 & 1080 & 40 & 879 & 1035 & -156 & 511 & 885 & -374 \\
$66-67$ & 1280 & 1050 & 230 & 796 & 786 & 10 & 608 & 678 & -70 \\
$67-68$ & 810 & 1590 & -780 & 613 & 1265 & -652 & 545 & 1001 & -456 \\
$68-69$ & 1210 & 1000 & 210 & 665 & 665 & 0 & 647 & 499 & 148 \\
$69-70$ & 1130 & 1020 & 110 & 619 & 801 & -182 & 539 & 852 & -313 \\
$70-71$ & 980 & 1340 & -360 & 722 & 574 & 148 & 625 & 523 & 102 \\
$71-72$ & 970 & 840 & 130 & 610 & 557 & 53 & 669 & 407 & 262 \\
$72-73$ & 1010 & 1300 & -290 & 496 & 1249 & -753 & 503 & 1211 & -708 \\
$73-74$ & 790 & 1410 & -620 & 632 & 683 & -51 & 605 & 730 & -125 \\
$74-75$ & 950 & 1400 & -450 & 505 & 980 & -475 & 747 & 459 & 288 \\
$75-76$ & 780 & 1500 & -720 & 444 & 1285 & -841 & 517 & 488 & 29 \\
$76-77$ & 850 & 1950 & -1100 & 371 & 1235 & -864 & 714 & 534 & 180 \\
$77-78$ & 790 & 2270 & -1480 & 406 & 1582 & -1176 & 441 & 551 & -110 \\
$78-79$ & 930 & 1450 & -520 & 573 & 1074 & -501 & 462 & 546 & -84 \\
$79-80$ & 880 & 1510 & 630 & 670 & 1034 & -364 & 390 & 725 & -335 \\
$80-81$ & 1100 & 990 & 110 & 577 & 1024 & -447 & 536 & 1188 & -652 \\
$81-82$ & 890 & 1580 & -630 & 323 & 1107 & -784 & 656 & 701 & -45 \\
$82-83$ & 1170 & 1720 & -550 & 211 & 1159 & -948 & 668 & 568 & 100 \\
$83-84$ & 710 & 1960 & -1250 & 235 & 1807 & -1572 & 455 & 538 & -83 \\
$84-85$ & 770 & 1320 & -550 & 263 & 1555 & -1292 & 478 & 1090 & -612 \\
$85-86$ & 1130 & 1650 & -520 & 663 & 1055 & -392 & 482 & 1151 & -669 \\
$86-87$ & 930 & 1270 & -340 & 432 & 1114 & -682 & 474 & 650 & -176 \\
$87-88$ & 1090 & 1700 & -610 & 791 & 1247 & -456 & 462 & 1106 & -644 \\
$88-89$ & 820 & 1280 & -460 & 691 & 1087 & -396 & 578 & 473 & 105 \\
$89-90$ & 920 & 1880 & -960 & 730 & 1508 & -778 & 596 & 544 & 52 \\
& & & & & & & & & \\
\hline & & & & & & & & &
\end{tabular}

lation season. This makes the inter-seasonal processes of glacier mass balance different from those on glaciers nourished primarily during the colder times of the year.

As a consequence of this temporal distribution of accumulation, frequent measurements are needed during the summer to ensure reliable estimates of the seasonal distribution of accumulation and ablation (Xie and Liu, 1993). For example, mass balance is measured on Ts. Tuyuksu two to four times each month in the summer, and only once in the winter. These measurements utilize 130-150 stakes and several snow pits. The annual accumulation, ablation and mass balance are calculated for $100 \mathrm{~m}$ elevation intervals. Similarly, on Urumqi glacier No. 1, mass balance is measured two or three times a month each summer using 69 stakes and several snow pits. Urumqi glacier No. 1 has two major branches; on each branch there are one longitudinal and eight transverse lines of stakes. In addition to such measurements, the precipitation gradient is measured in glacierized areas in the vicinity of glacier Karabatkak, and is used, in conjunction with the precipitation data, to obtain a separate estimate of the mass input. This is used, together with runoff data, to check the mass-balance measurements.

\section{METHODS}

Most studies detect abrupt changes in climate by using statistical tests. Generally, the mean values of climatic parameters are used to determine whether there has been a jump. This approach is used on glacier mass-balance data in this paper. Both the moving $t$-test (MTT) and MannKendall rank test (MKRT) are used, and the results are compared.

In the MTT, if the difference between means over two adjacent time intervals reaches a stipulated statistical significance level, an abrupt change is inferred to have occurred. Whether a change is detected depends on the choice of significance level. Thus, suppose a stochastic variable sequence of annual balance is divided into two sub-sets, $x_{1}$ and $x_{2}$. Let $\mu_{i}, S_{i}$ and $n_{i}$ represent the mean, variance and sample size of the two sub-sets $(i=1,2)$, respectively. The data are then analyzed using the null hypothesis $H_{0}: \mu_{1}=\mu_{2}$ and the test statistic, $t_{0}$, is calculated as follows:

$$
t_{0}=\frac{\mu_{1}-\mu_{2}}{S_{\mathrm{p}}\left[\frac{1}{n_{1}}+\frac{1}{n_{2}}\right]^{\frac{1}{2}}}
$$

where

$$
S_{\mathrm{p}}=\left[\frac{\left(n_{1}-1\right) S_{1}^{2}+\left(n_{2}-1\right) S_{2}^{2}}{n_{1}+n_{2}-2}\right]^{\frac{1}{2}}
$$

is the sample covariance. Because we are interested in decadal time-scales, $n_{1}=n_{2}=10$. It is evident that $t_{0} \sim t\left(n_{1}+n_{2}-2\right)$. Given the significance level $\alpha$ and its corresponding critical value $t_{\alpha}$, the null hypothesis $H_{0}$ will be rejected for $\left|t_{0}\right|>t_{\alpha}$. This would suggest that a jump is present between the two neighboring sub-sets.

Figure 2 is the time series of annual balance from 1956- 


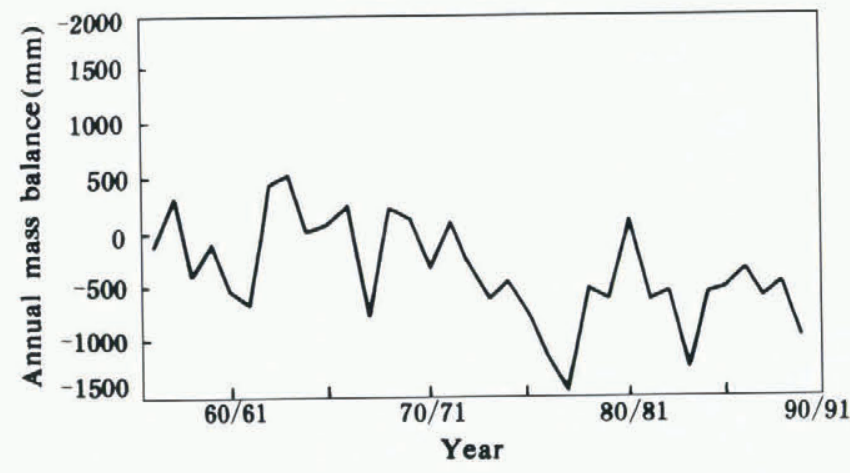

Fig. 2. Time series of annual balance from 1956-57 through 1989-90 for glacier Ts. Tuyuksu.

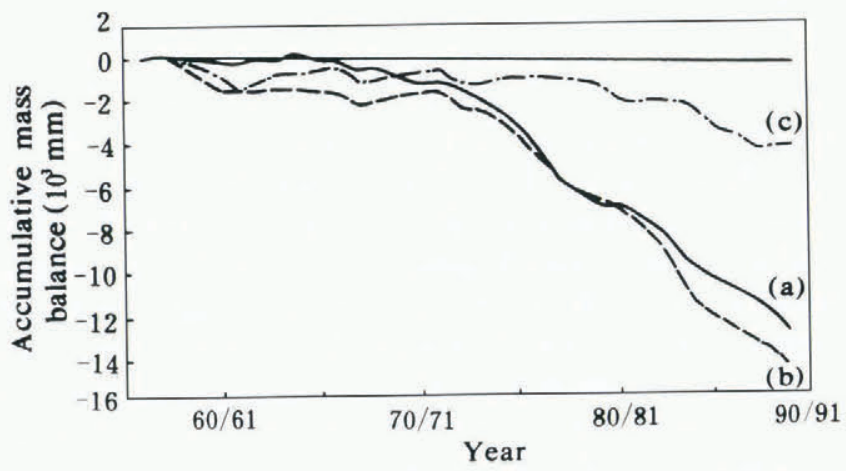

Fig. 3. Accumulative curve of annual balance for glaciers (a)

Ts. Tuyuksu; (b) Karabatkak; (c) Urumqi glacier No. 1.

57 through 1989-90 for glacier Ts. Tuyuksu. Curve (a) of Figure 3 is the corresponding accumulative curve for 34 years. Curves (b) and (c) of Figure 3 show similar data for glaciers Karabatkak and Urumqi glacier No. 1, respectively. It appears that there was a pronounced change in the early to mid-1970s. It is, however, not always as easy as this to distinguish when accumulative curves are atypical (see Letréguilly and Reynaud, 1990, fig. 3). The statistical tests applied here, however, can detect such changes. Figure 4 shows results of the MTT test using $n_{1}=n_{2}=10$ years. It is clear that a jump occurs in the early 1970 s on glaciers Ts. Tuyuksu and Karabatkak, and probably in the late 1970s on Urumqi glacier No. 1 , and that their tests reach the significance level $\alpha=0.05$ in the first two cases.

If there is little difference between the magnitude of $n_{i}$ and the length of the entire sequence, jumps near or at the ends of the sequence cannot be detected. The non-parametric MKRT test partly avoids this weakness. It is generally agreed that the detection range of MKRT is broader and the timing more precise (Goossens and Berger, 1987). The null hypothesis of MKRT is $H_{0}$ : there is no trend change in the sequence of mass balance $x_{1}, x_{2}, \ldots, x_{\mathrm{N}}$. For each element $x_{i}$ the numbers $m_{i}$ of elements $x_{j}$ preceding it $(j<i)$ such that $\left(x_{j}<x_{i}\right)$ are computed. Then, one assumes that the test statistic $d_{\mathrm{k}}$, its expected value $E\left[d_{k}\right]$, and variance $\operatorname{var}\left[d_{k}\right]$, are as follows:

$$
\begin{aligned}
d_{k} & =\sum_{i=1}^{k} m_{i} \quad(2 \leq k \leq N) \\
E\left[d_{k}\right] & =\frac{k(k-1)}{4} \\
\operatorname{var}\left[d_{k}\right] & =\frac{k(k-1)(2 k+5)}{72}
\end{aligned}
$$

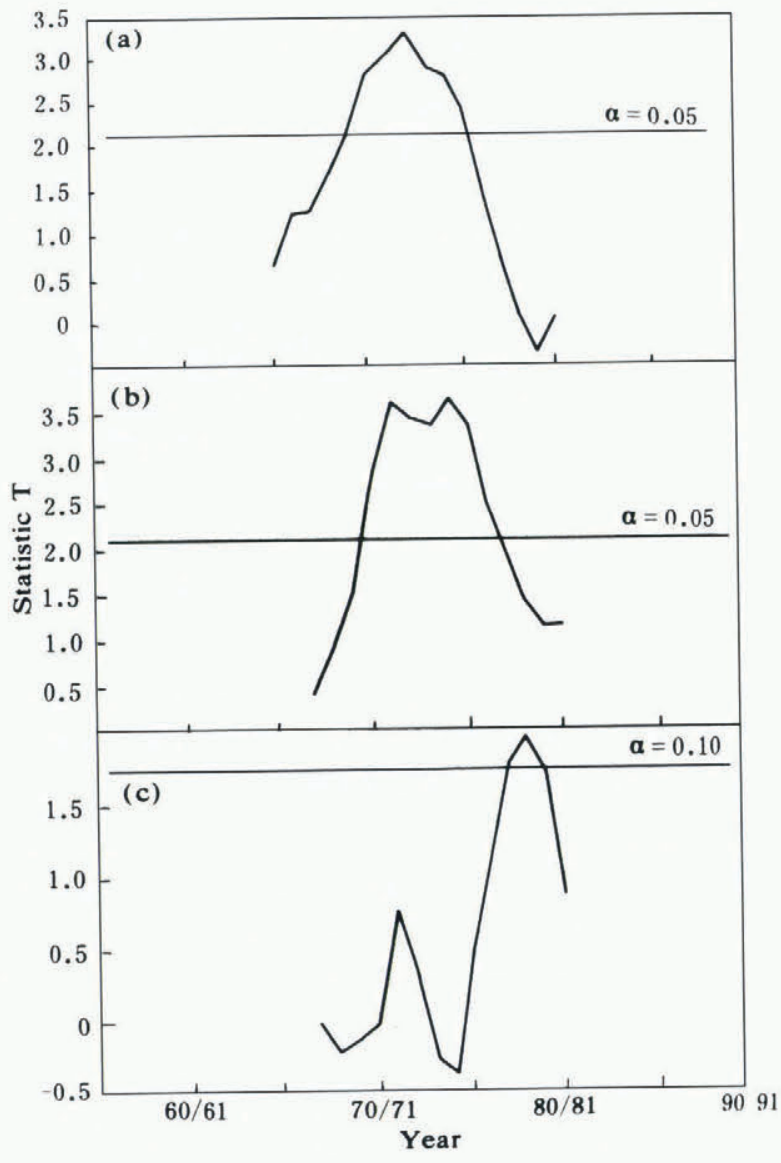

Fig. 4. Abrupt change in annual balance detected using MTT for glaciers (a) Ts. Tuyuksu; (b) Karabatkak; (c) Urumqi glacier No. 1. (Solid horizontal line is the critical value corresponding to the significance level shown.)

Normalizing yields:

$$
u\left(d_{k}\right)=\frac{d_{k}-E\left[d_{k}\right]}{\sqrt{\operatorname{var}\left[d_{k}\right]}}
$$

where $u\left(d_{k}\right)$ has a normal distribution, and the probability $\alpha_{1}=\operatorname{prob}\left(|u|>\left|u\left(d_{k}\right)\right|\right)$ can be determined using tables or calculations. If $\alpha_{0}$ is the significance level of the test (e.g. $0.05)$, the null hypothesis is accepted or rejected depending on whether $\alpha_{1}$ is greater or less than $\alpha_{0}$. When values of $u\left(d_{k}\right)$ violate the null hypothesis, the existence of an increasing $\left(d_{k}>0\right)$ or decreasing $\left(d_{k}<0\right)$ trend in the data will be indicated.

Figure 5 presents the results of the MKRT test. Curves $\mathrm{Cl}$ are constructed from $u\left(d_{k}\right)$, except that $u\left(d_{1}\right)=0$. The same procedure can be used for the retrograde series, where $m_{\mathrm{i}}$ ' represents the numbers of the elements for $x_{i}>x_{j}(i \leq j \leq N)$. If $i^{\prime}=N+1-i$, then $m_{i}=m_{i}^{\prime}$ and

$$
u^{*}\left(d_{i}\right)=-u\left(d_{i}^{\prime}\right) \quad\left(i, i^{\prime}=1,2, \ldots, N\right) .
$$

The variation of the sequence $u^{*}\left(d_{k}\right)$ is shown by C2 in Figure 5. The approximate time of an abrupt change that occurs within the confidence interval is represented by the intersection of the direct and backward curves, $\mathrm{Cl}$ and $\mathrm{C} 2$.

\section{RESULTS AND DISCUSSION}

The results of applying these techniques to the mass-balance records of the three glaciers studied are listed in Table 2. All tests detected jumps with significance levels $\alpha=0.05$, except that for Urumqi glacier No. 1, which yielded a significance 


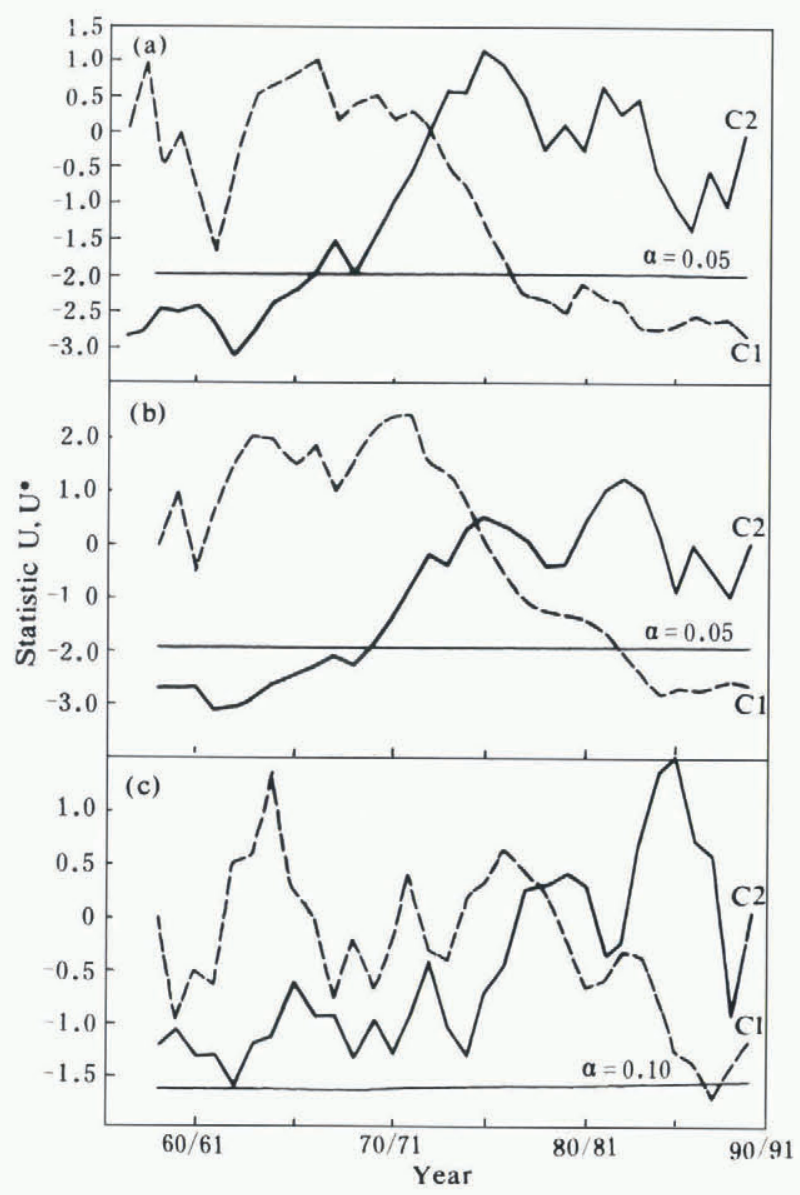

Fig. 5. Abrupt change in annual balance detected using MKRT for glaciers (a) Ts. Tuyuksu; (b) Karabatkak; (c) Urumqi glacier No. 1. (C1 and C2 are the variation curves for forward and backward sequences of the statistic $u$ and $u^{*}$, and the solid horizontal line is the critical value corresponding to the significance level shown.)

level at 0.10 only. It is evident that, although the annual balance in this region has been predominantly negative since the $1950 \mathrm{~s}$, the negative-balance rate increased after the mid-1970s. For example, the mean balance rates for glacier Ts. Tuyuksu are -81 and $-667 \mathrm{~mm}^{-1}$ water equivalent before and after the jump, respectively. The difference between them is $-586 \mathrm{~mm} \mathrm{a}^{-1}$, being 1.83 times larger than the mean of $-374 \mathrm{~mm} \mathrm{a}^{-1}$ for the entire 34 years. It appears

Table 2. Detected results of abrupt change for three glaciers in the Tien Shan Mountains

\begin{tabular}{|c|c|c|c|}
\hline $\begin{array}{l}\text { Glacier name } \\
\text { (PSFG code) }\end{array}$ & $\begin{array}{l}\text { Ts. Tuyuksu } \\
\text { (SL05075) }\end{array}$ & $\begin{array}{l}\text { Karabatkak } \\
\text { (SU05080) }\end{array}$ & $\begin{array}{l}\text { Urumqi glacier.No. } 1 \\
\text { (CN0010) }\end{array}$ \\
\hline Lat. $(\because \mathrm{N})$ & 43.00 & 42.06 & 43.05 \\
\hline Long. $(\because \mathrm{E})$ & 77.06 & 78.18 & 86.49 \\
\hline Area $\left(\mathrm{km}^{2}\right)$ & 3.14 & 4.56 & 1.84 \\
\hline Jump year (MKRT) & $1972-73$ & $1974-75$ & $1977-78$ \\
\hline Jump year (MTT) & $1972-73$ & $1974-75$ & $1977-78$ \\
\hline Significance level & 0.05 & 0.05 & 0.10 \\
\hline $\begin{array}{l}\text { Average mass balance } \\
\left.\text { Before jump ( } \mathrm{mm} \mathrm{a}^{-}\right)\end{array}$ & -81 & -208 & -42 \\
\hline $\begin{array}{l}\text { Average mass balance } \\
\text { After jump }\left(\mathrm{mm} \mathrm{a}^{-1}\right)\end{array}$ & -667 & -766 & -254 \\
\hline Difference $\left(\mathrm{mm} \mathrm{a}^{-1}\right)^{*}$ & -586 & -558 & -212 \\
\hline Percent change $(\%)^{\dagger}$ & 183 & 110 & 176 \\
\hline
\end{tabular}

\footnotetext{
* Mean difference of annual balance before and after jump year.
}

${ }^{\dagger}$ Percent difference relative to overall mean annual mass balance.

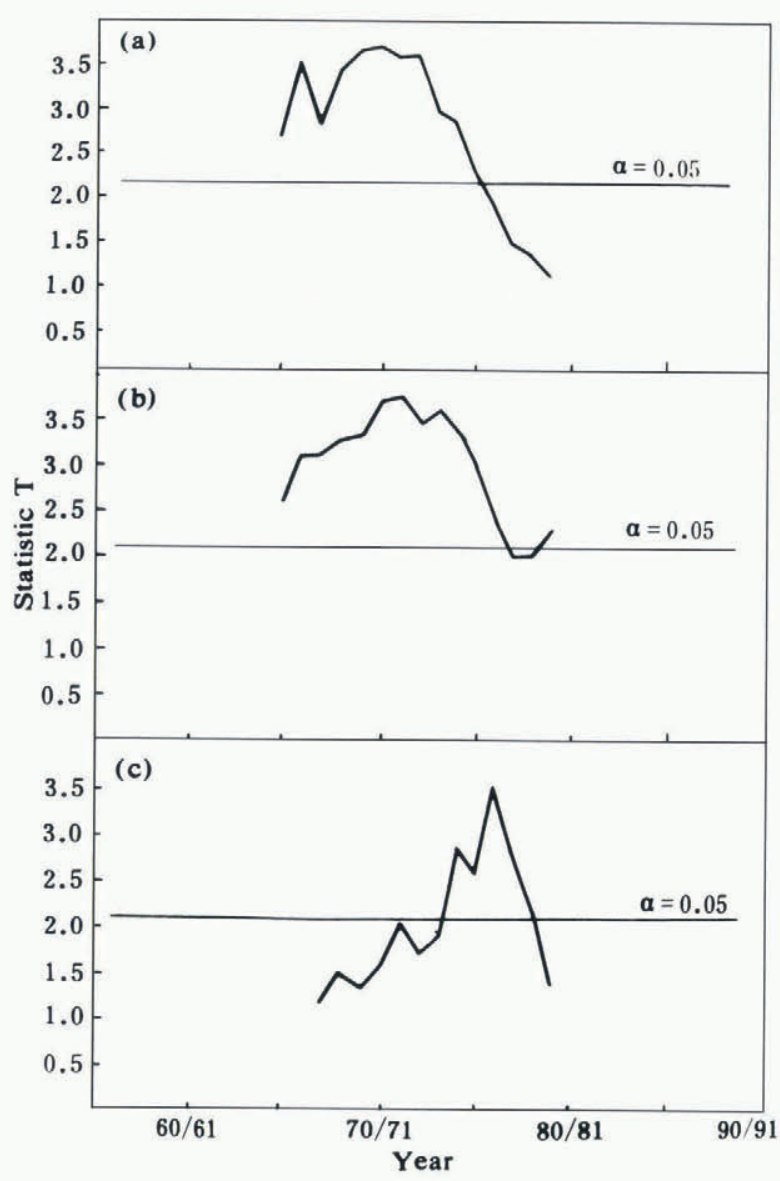

Fig. 6. Abrupt change in annual accumulation detected using MT T for glaciers (a) Ts. Tuyuksu, (b) Karabatkak; (c) Urumqi glacier No. 1. ( For explanation, see Figure 4.)

that the climatic environment in the Tien Shan Mountains became warmer and drier after the mid-1970s, and that this change was superimposed on the overall warmer trend in this century.

Results of analyses of the annual accumulation and ablation series separately show that the jump years are 1970-71 and 1972-73, respectively, for Ts. Tuyuksu; 1971-72 and 1974 - 75 for glacier Karabatkak; and 1975-76 and 197778 for Urumqi glacier No. 1 (Figs 6-9). Note that the jump year for annual ablation coincides with, or follows by 1 year, that of annual balance (Table 2), but follows that for accumulation by $2-3$ years. Note also (Table 3 ) that approximately two-thirds of the difference in annual balance is a result of a change in annual ablation; the other one-third is due to a change in annual accumulation. The mass balance incorporates the effects of both annual accumulation and ablation. Thus, the abrupt decrease in annual balance for these three glaciers was caused more by the variation in annual ablation than by that in accumulation.

Normally, snow accumulation is concentrated in the winter and ablation in the summer, so annual accumulation and ablation vary with winter precipitation and summer temperature, respectively. However, as noted, this is not the case in this part of the Tien Shan Mountains. The record of summer temperature and annual precipitation at the Daxigou meteorological station $\left(43^{\circ} 06^{\prime} \mathrm{N}, 86^{\circ} 50^{\prime} \mathrm{E}\right.$; $3539 \mathrm{~m}$ a.s.1.), near Urumqi glacier No. 1, are shown in Table 4. Analyses of these data by MTT and MKRTare shown in Figures 10 and 11. It is clear that there are no abrupt changes even at the 0.10 significance level, in either case. The differences in the means before and after $1977-78$ are only $0.2^{\circ} \mathrm{C}$ and $-19 \mathrm{~mm}$, 


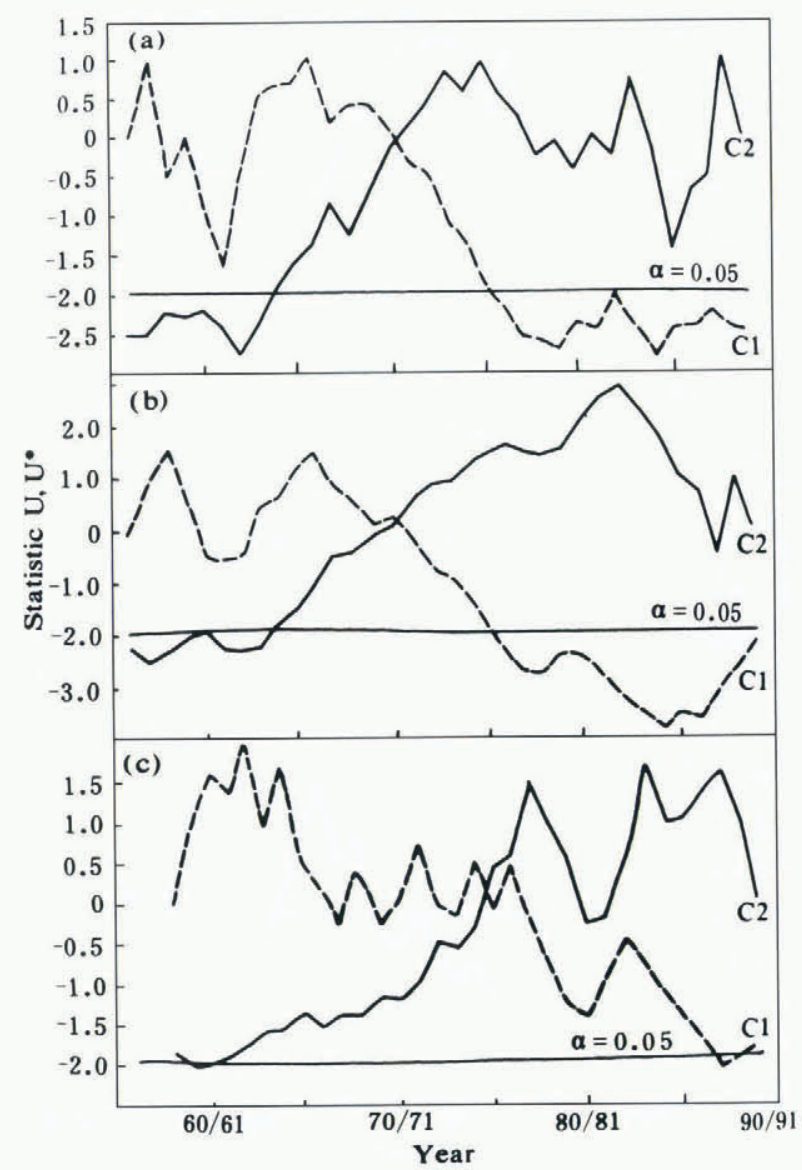

Fig. 7. Abrupt change in annual accumulation detected using MKRT for glaciers (a) Ts. Tuyuksu, (b) Karabatkak; Urumqi glacier No. 1. (For explanation, see Figure 5.)

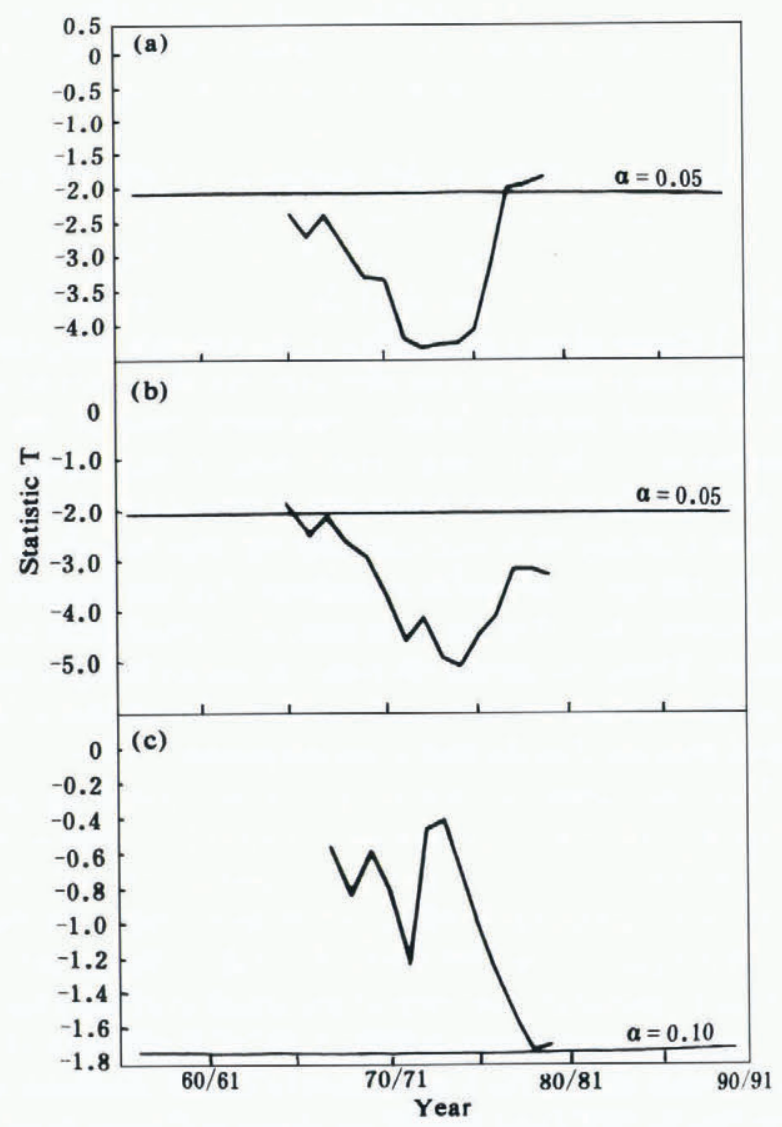

Fig. 8. Abrupt change in annual ablation detected using MTT for glaciers (a) Ts. Tuyuksu, (b) Karabatkak; (c) Urumqi glacier No. 1. (For explanation, see Figure 4.)
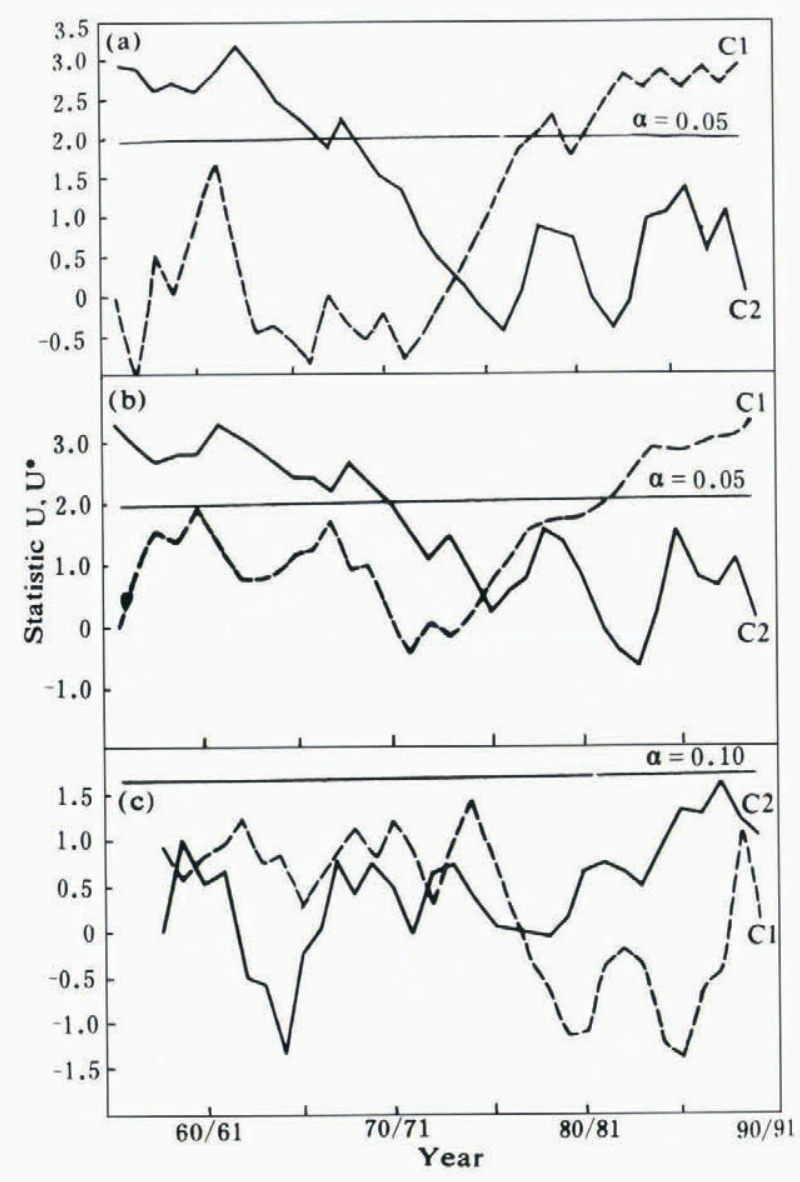

Fig. 9. Abrupt change in annual ablation detected using MKRT for glaciers (a) Ts. Tuyuksu, (b) Karabatkak; (c) Urumqi glacier No. 1. (For explanation, see Figure 5.)

respectively. This lack of evidence for abrupt changes may be attributed to the unusual inter-seasonal distribution of precipitation mentioned above. Under such conditions, both accumulation and ablation may be influenced by either precipitation or temperature, or both. For example, if there is no change in precipitation in the summer, an increase in temperature will not only increase ablation but also decrease accumulation due to a lower ratio of solid to liquid precipitation. However, if an increase in temperature and a decrease in precipitation occur together, there will be a feed-back between ablation and accumulation due to the dependence of snowline elevation on snow accumulation. Thus, a lower than normal snowfall results in a higher snowline and a greater increase in ablation because, due to its lower albedo, ice normally melts $4-5$ times faster than snow (personal communication from W. Tangborn, 1997). Therefore, although no statistically significant abrupt

\section{Table 3. Detected results of annual accumulation and ablation for three glaciers}

Glacier Jump year Mean annual accumulation Mean annual ablation for Before After Difference Before After Difference annual jump jump (\%of jump jump (\% of balance total diff.) total diff.)

$\mathrm{mm} \mathrm{mm} \quad \mathrm{mm} \mathrm{mm}$

$\begin{array}{lccccccc}\text { Ts. Tuyuksu } & 1972-73 & 1092 & 915 & 177(30) & 1168 & 1573 & 410(10) \\ \text { Karabatkak } & 1974-75 & 667 & 492 & 175(30) & 874 & 1258 & 384(70) \\ \text { Urumqi No. 1 } & 1977-78 & 597 & 519 & 78(37) & 639 & 773 & 134(63)\end{array}$


Table 4. The records at Daxigou meteorological station

Year

$\begin{array}{cc}\text { Summer } & \text { Annual } \\ \text { lemperature } & \text { precipitation }\end{array}$ *

C

$\mathrm{mm}$

\begin{tabular}{|c|c|c|}
\hline $58-59$ & 3.8 & \\
\hline $59-60$ & 4.0 & 472.8 \\
\hline $60-61$ & 3.9 & 423.6 \\
\hline $61-62$ & 4.6 & 434.5 \\
\hline $62-63$ & 4.0 & 444.2 \\
\hline $63-64$ & 4.1 & 495.5 \\
\hline $64-65$ & 4.2 & 444.2 \\
\hline $65-66$ & 4.3 & 502.3 \\
\hline $66-67$ & 3.6 & 373.8 \\
\hline $67-68$ & 3.7 & 428.0 \\
\hline $68-69$ & 3.7 & 377.6 \\
\hline $69-70$ & 3.9 & 471.0 \\
\hline $70-71$ & 3.8 & 380.5 \\
\hline $71-72$ & 3.8 & 465.5 \\
\hline $72-73$ & 4.3 & 489.4 \\
\hline $73-74$ & 4.4 & 354.0 \\
\hline $74-75$ & 3.9 & 418.4 \\
\hline $75-76$ & 3.0 & 446.2 \\
\hline $76-77$ & 4.6 & 462.5 \\
\hline $77-78$ & 4.3 & 383.2 \\
\hline $78-79$ & 3.9 & 436.1 \\
\hline $79-80$ & 4.4 & 417.7 \\
\hline $80-81$ & 4.0 & 360.8 \\
\hline $81-82$ & 3.7 & 448.6 \\
\hline 8283 & 3.7 & 485.9 \\
\hline $83-84$ & 4.0 & 410.7 \\
\hline $84-85$ & 3.9 & 368.9 \\
\hline $85-86$ & 4.5 & 339.7 \\
\hline $\begin{array}{ll}86 & 87\end{array}$ & 4.1 & 353.8 \\
\hline $87-88$ & 4.3 & 423.5 \\
\hline 88-89 & 3.5 & 501.5 \\
\hline $89-90$ & 4.4 & 462.6 \\
\hline
\end{tabular}

* September to August.

changes occur in annual precipitation and summer temperature, the feed-back amplifies the effect, resulting in a significant change in mass balance.

In the basin of Urumqi glacier No. 1, appreciable

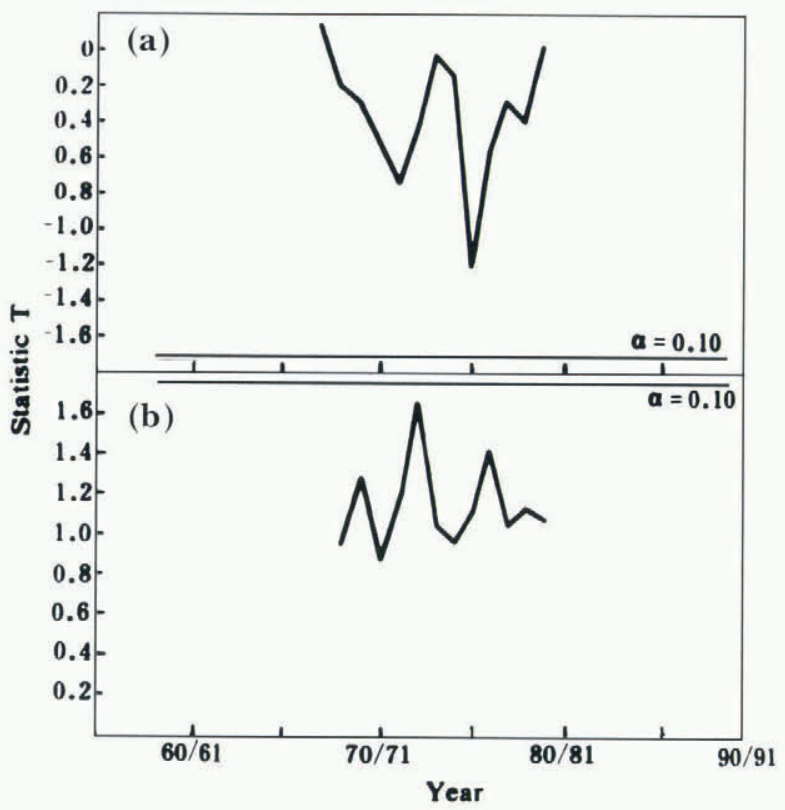

Fig. 10. Abrupt change in (a) summer temperature and (b) annual precipitation detected using MTT for Urumqi glacier No. 1 .

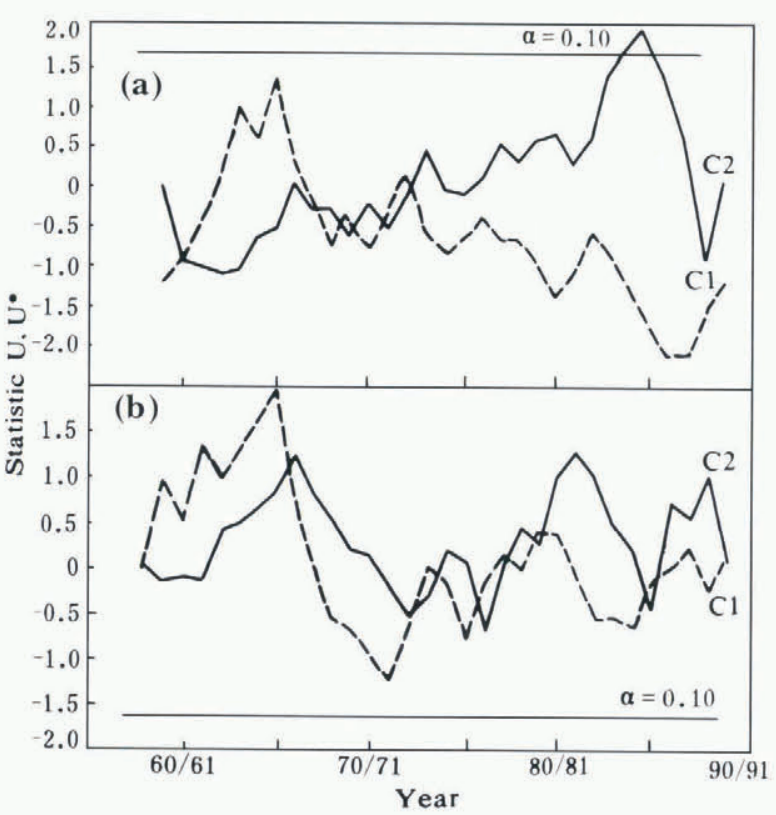

Fig. 11. Abrupt change in (a) summer temperature and (b) annual precipitation detected using MKRT for Urumqi glacier No. 1.

changes in annual precipitation and summer temperature are detected in 1972-73 and 1976-77 (Figs 10 and 11). It is noteworthy that 1976-77 is nearer the jump year for annual balance and ablation than that for accumulation. This again means that an increase in temperature dominated the abrupt change in mass balance, since most of the change is caused by ablation. The meteorological records at both Mynzhilki $43^{\circ} 05^{\prime}$ N, $77^{\circ} 04^{\prime}$ E; 3017 ma.s.l.) and Tien Shan $\left(41^{\circ} 55^{\prime} \mathrm{N}, 78^{\circ} 14^{\prime} \mathrm{E}\right.$; $3614 \mathrm{~m}$ a.s.l. $)$ meteorological stations, near glacier Ts. Tuyuksu and Karabatkak, respectively, show similar characteristics (Liu and Han, 1992). A jump in summer temperature occurred in 1972-73 at Mynzhilki station that also reached the 0.05 significance level. Therefore, it seems that abrupt changes in mass balance for these glaciers are caused mainly by an increase in the summer temperature over the Tien Shan Mountains.

\section{CONGLUSIONS}

An abrupt change in the coupled ocean-atmosphere system over the tropical Pacific during the mid-1970s was both observed and simulated by a general circulation model (Graham, 1994). This led to obvious changes in the largescale boreal winter circulation pattern over the north Pacific, marked by a southward shift and intensification of the Aleutian Low and of the prevailing westerlies over the mid-latitude central and eastern Pacific. A difference in the $700 \mathrm{hPa}$ heights between 1970-71 and 1975-76, and 1976-77 and 198182 in the Tien Shan Mountains is confirmed by a $t$-test at a significance level $\alpha=0.05$. Thus, the abrupt change in glacier mass balance in the Tien Shan Mountains, in effect, corresponds to that event.

Variations in the positions of glacier fronts are often used to deduce climate change on longer time-scales, because these data are easy to collect, although the response lags the climate change. Mass balance, however, reflects the preceding year's climate. Thus, it is more sensitive, as it directly links a glacier to its climatic environment. This research further suggests that monitoring mass balance can provide, 
directly, information on abrupt changes in climatic environments on short time-scales.

\section{ACKNOWLEDGEMENTS}

I am indebted to Professor Shi for his encouragement and discussions. I should also like to thank W. Tangborn of the Iceberg Monitoring Project, University of Washington, and D. Cayan, Climate Research Division, Scripps Institution of Oceanography, for their detailed reviews and many valuable suggestions for improvement of the manuscript. I should especially like to thank sincerely R. LeB. and A. P. Hooke for conscientious editing and retyping. This study was supported by the Chinese Academy of Sciences project "Basic research on dynamic changes in the cryosphere."

\section{REFERENCES}

Barry, R. G. 1985. The cryosphere and climatic change. In MacCracken, M. C. and F. M. Luther, eds. Detecting the climatic effects of increasing carbon dioxide. Washington, DC, U.S. Department of Energy, 109-148. (Report DOE/ER-0235.)

Dyurgerov, M. B., Liu Chaohai and Xie Zichu. 1995. Oledenenie Tyan'-Shanya [Tien Shan glaciers]. Moscow, Vsesoyuznyy Institut Nauchnoy i Tekhnicheskoy Informatsii (VINITI).

Goossens, C. and A. Berger. 1987. How to recognize an abrupt climate change? In Berger, W. H. and L. D. Labeyrie, eds. Abrupt climatic change: evidence and implications. Dordrecht, etc., D. Reidel Publishing Co., 31-45. (NATO ASI Series C: Mathematical and Physical Sciences 216.)

Graham, N. E. 1994. Decadal-scale climate variability in the Tropics and North Pacific during the 1970s and 1980s: observations and model results. Climate Dyn., 10, 135-162.
Haeberli, W., ed. 1985. Fluctuations of glaciers 1975-1980 (Vol. IV). Paris, International Commission on Snow and Ice of the International Association of Hydrological Sciences/Unesco.

Haeberli, W. and M. Hoelzle, eds. 1993. Fluctuations of glaciers 1985 - 1990 ( Vol. VI). Wallingford, Oxon., IAHS Press; Nairobi, UNEP; Paris, Unesco.

Haeberli, W. and P. Müller, eds. 1988. Fluctuations of glaciers 1980-1985 (Vol.V). Wallingford, Oxon., IAHS Press; Nairobi, UNEP; Paris, Unesco.

Kasser, P. 1967. Fluctuations of glaciers 1959-1965 [Vol. I]. Paris, International Commission of Snow and Ice of the International Association of Scientific Hydrology/Unesco.

Kasser, P., ed. 1973. Fluctuations of glaciers 1965-1970 [Vol. II]. Paris, International Commission on Snow and Ice of the International Association of Hydrological Sciences/Unesco.

Letréguilly, A. and L. Reynaud. 1990. Space and time distribution of glacier mass-balance in the Northern Hemisphere. Arct. Alp. Res., 22 (1), 43-50.

Liu Chaohai and Han Tianding. 1992. Relation between recent glacier variations and climate in the Tien Shan Mountains, Central Asia. Ann. Glaciol., 16, 11-16.

Maasch, K. A. 1988. Statistical detection of the mid-Pleistocene transition. Climale Dyn., 2, 133-143.

Meier, M. F. 1965. Glaciers and climate. In Wright, H. E. and D. G. Frey, eds. The Quaternary of the United States. Princeton, NJ, Princeton University Press, 795805.

Müller, F., ed. 1977. Fluctuations of glaciers 1970-1975 (Vol. III). Paris, International Commission on Snow and Ice of the International Association of Hydrological Sciences/Unesco.

Trenberth, K. E. 1990. Recent observed interdecadal climatic change in the Northern Hemisphere. Bull. Am. Meteorol. Soc., 71, 988-993.

Wood, F. B. 1988. Global alpine glacier trends, 1960 s to 1980s. Arct. Alp. Res., $20(4), 404-413$.

Xie Zichu and Liu Chaohai. 1993. Measurement and method and main characteristics of the glacier mass balance in Asia. International Association of Hydrological Sciences Publication 212 (Symposium at Yokohama 1993 - Exchange Processes at the Land Surface ), $49-58$.

Yamamoto, R., T. Iwashima and N. K. Sanag. 1985. Climatic jumps, a hypothesis in climate diagnosis. J. Meteorol. Soc. Jpn, 63, 1157-1160. 